\title{
PARACOCCIDIOIDOMICOSE OCULAR RELATO DE UM CASO COM CORIORRETINITE POSTERIOR
}

\author{
Walter Oleschko ARrUDA (1), Marco Antonio Santinl CANTO (2), Glovanni LODDO (3), Vanda \\ Fátima REBUFFI (3) \& Moema de Araújo CARDOSo (1)
}

\begin{abstract}
R E S U M O
É descrito um caso de paracoccidioidomicose com envolvimento ocular. Pela primeira vez descreve-se a presença do fungo em lesão granulomatosa de coróide. Os Autores revêm os casos de paracoccidioidomicose com acometimento do trato uveal já descritos na literatura e analisam os achados clínicos e anátomo-patológicos destes e do presente relato.
\end{abstract}

UNITERMOS: Paracoccidioidomicose humana - Olho - Coriorretinite posterior

\section{NTROD U G A O}

A paracoccidioidomicose é uma infecção granulomatosa crônica produzida pelo Paracoccidioides brasiliensis, sendo descrita pela primeira vez no Brasil pelo Prof. ADOLPHO LUTZ, em $1908^{8}$. Desde então as mais variadas formas clínicas da doença, com o acometimento de diversos órgãos e sistemas têm sido relatadas. Acredita-se que a porta de entrada no hospedeiro humano seja o trato respiratório, havendo posterior disseminação sistêmica por via hematogennica $e /$ ou linfática 1,7 .

Em relação aos olhos e anexos a paracoccidioidomicose acomete com maior frequiência as pálpebras e conjuntivas, geralmente dentro de um quadro disseminado da doença sendo rara a localização primária da lesão micótica no globo ocular 6 .

O comprometimento do trato uveal pela blastomicose é pouco frequiente e existem 4 casos descritos na literatura disponível.

Os Autores descrevem um caso de paracoccidioidomicose ocular com coriorretinite posterior e pela primeira vez a detecção do fungo em lesão granulomatosa de coróide.

\section{apresentaço do caso}

P.M., masculino, 56 anos, lavrador, foi admitído com queixa de cefaléia, dor severa e perda de visão de olho direito, com inicio há 1 mês. Ainda referia astenia, anorexia, emagrecimento e tosse com expectoração não purulenta. Fumante de cigarros de palha, não era etilista.

Ao exame físico geral era um homem emagrecido, bem hidratado, com aumento do diâmetro ântero-posterior do tórax. Sua pressão arterial oscilava entre $90 / 60$ e $80 / 50 \mathrm{mmHg}$, sem hipotensão postural, pulso 92 b.p.m., rítmico, afebril e eupnéico. Havia lesões moriformes em lábio superior e mucosa bucal direita, sem linfonodomegalia.

O olho direito era totalmente amaurótico, congesto, com catarata secundária, evidenciável à biomicroscipia.

Os exames Iaboratoriais revelavam hemo. globina $13,1 \mathrm{~g} / \mathrm{dl}$, VG $41,2 \%, 15.500$ leucócitos/ $\mathrm{mm}^{3}, 4 \%$ bastões, $64 \%$ segmentados, $1 \%$ eosi.

(1) Departamento de Clínica Médica da Universidade Federal do Paraná, Curitiba, Paraná, Brasil

(2) Departamento de Cirurgia (Oftalmologia) da Universidade Federal do Paraná.

(3) Departamento de Patologia Médica da Universidade Federal do Paraná. 
ARRUDA, W. O.; CANTO, M. A. S.; LODDO, G.: REBUFF, V. F. A CARDOSO, M. de A. - Paracoceldioidomicose oculsr. Reisto de um caso com coriorretinite posterior. Rev. Inst. Med. trop. são Paulo, 25:190-193, 1986.

nófilos, $21 \%$ linfócitos, $10 \%$ monócitos, fndices hematimétricos normais, plaquetas normais, VHS $95 \mathrm{~mm}$ (Westergreen), creatinina $0,8 \mathrm{mg} /$ dl, glicose $84 \mathrm{mg} / \mathrm{dl}$ (jejum), sódio $139 \mathrm{mEq} / 1$, potássio $4,1 \mathrm{mEq} / 1$, mucoproteinas $11,5 \mathrm{mg} / \mathrm{dl}$ tirosina, proteina $\mathrm{C}$ reativa positiva, PPD negativo, imunofluorescência para paracoccidioido. micose $1 / 128$, fixação de complemento $1 / 32$, precipitaçăo ++ . Bacterioscopia para BAAR no escarro negativa, pesquisa de fungos revelou presença de leveduras com caracteristicas fisicas de Paracoccidióides brasiliensis, confirmada pela cultura. Radiografia de tórax mostrava presença de lesōes fibróticas compativeis com blastomicose sul-americana. Dosagens de 17-hidroxiesteroides e 17-cetosterbides na urina de 24 horas foram de $3,2 \mathrm{mg}$ e $4,2 \mathrm{mg}$ respectivamente. Foi iniciada terapêutica com anfotericina B e hidrocortisona. Uma semana após, devido à dor intratável, sofreu enucleaçâo do olho D.

No estudo anátomo-patológico da peç, à macroscopia, destaca-se o preenchimento da càmara vitrea por tecido predominantemente vermelho escuro, friável, entremeado por áreas amareladas, opacas, como também discreta opacificaçăo da córnea, onde, ao nivel do limbo há orificio com $0,9 \mathrm{~cm}$ de diâmetro, cujas bordas sāo irregulares, acastanhadas e friáveis.

A microscopia a câmara vítrea é totalmente preenchida por hemorragia entremeada por tecido de granulaçăo abundante, onde destacam-se granulomas frouxos, constituidos por histiócitos epitelióides e celulas gigantes multinucleadas tipo Langhans ou tipo corpo estra. nho, acompanhados de intensa exsudaçäo neutrofilica (Figs, 1 e 2). Nestas áreas săo evidenciáveis inúmeras estruturas arredondadas de tamanhos variáveis envoltas por cápsula refringente, que pela impregnaçăo argêntica (Grocott) preenchem os critérios morfologicos caracteristicos do Paracoccidióides brasiliensis (Fig. 3). A retina e parte da coróide săo também alteradas pelo processo inflamatório ou mesmo substituidas por tecido conjuntivo fi. broso denso. Alteraçoes semelhantes com predomínio do tecido de granulaçăo e da reaçāo inflamatória săo também observadas ao nível de corpo ciliar.

O estudo microscópico da biópsia de mucosa labial demonstra, além de discretas altera- çōes epiteliais, a presença de granulomas ao nivel de córion, de constituiçăo semelhante aos

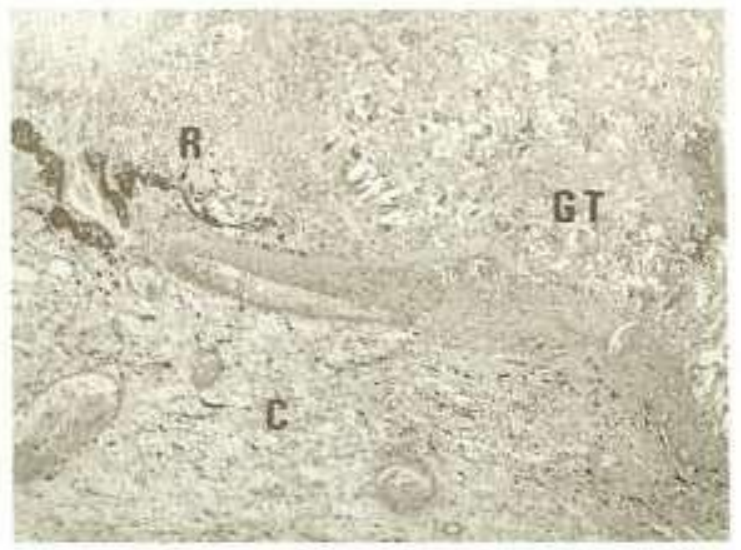

Pig. 1 - Destruição dà retina $(R)$ o perte da coróide (C) bem como preenchimento da cimara vitrea por tecido de eranulacáo (GT) (H. \& E. Obj. 4 x)

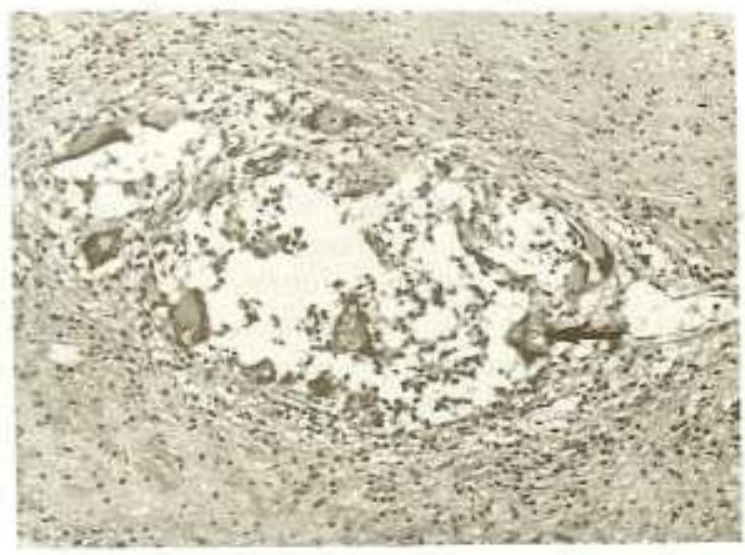

Pig. 2 - Granulomas onde destacam-5e celulas gigantes histiocitilias multinuclesdas que cantém microorganismos identificados como Parscoecidióldes brasillensts em seu interior (sets) (B \& E Obj $10 \mathrm{x}$ )

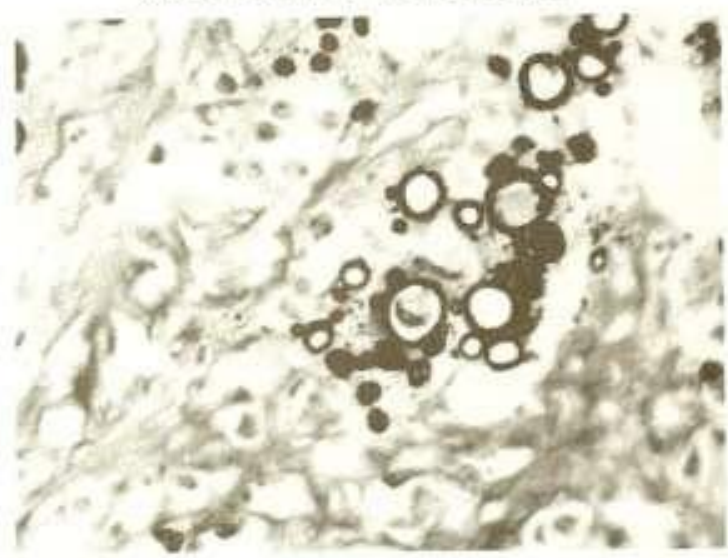

Fig. 3 - Impregnaciio argentica onde o Paracoccidibides braalliensin of fecilmente evidencidvel (Grocott - obj. 45 x) 
ARRuDA, W. O.; CANTO, M. A. S.; LODDO, G.; REBUFF, V. P. \& CARDOSO, M. de A. - Paracceidioldomicose ocular. Reinto de um caso com coriorratinite postarior. Rev. Inst, Med. trop. Siso Paulo, 2B!190-193, 1986,

descritos em globo ocular, onde os fungos stio também evidenciáveis (Fig. 4).

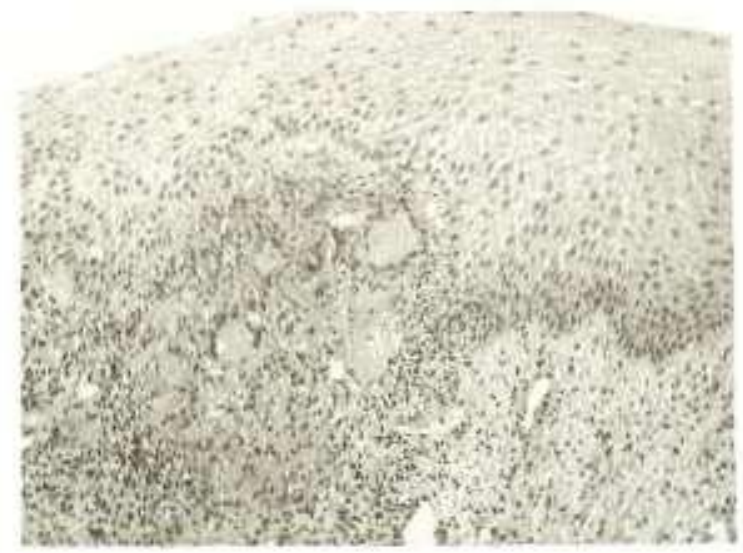

Fie. - Detalhe da mucosa lsbial onde, ao nivel de cobrion ha granuloma com numerosss cellalss gigantes his. tiocitarias multimucieadas predominantemente do tipo tanghans (H. \& E obj. $10 \mathrm{x}$ )

Duas semanas após à cirurgia o paciente desenvolveu um quadro súbito de hemiparesia esquerda desproporcional, com discreta disar. tria. Punçåo liquórica lombar mostrou pressăo liquórica normal, eritrócítos 0 , leucócitos $2 / \mathrm{mm}^{3}$, mononucleares, proteina $25 \mathrm{mg} / \mathrm{dl}$, gllcose $82 \mathrm{mg} / \mathrm{dl}$. Culturas de liquor para BAAR e fungos negativas. Testes sorológicos para toxoplasmose, cisticercose e VDRL negativos. Fol
O paciente teve alta no $76^{\circ}$ dis de interna. çà, após completar infusío endovenosa total de $2,0 \mathrm{~g}$ de anfotericina $\mathrm{B}$, fazendo uso de prednisona $7,5 \mathrm{mg} /$ dia e sulfametoxazol + trimetoprim, com bom estado geral, desaparecimento das lesŏes bucais, niveis tensionais normalizß. dos e com boa recuperaçāo do déficit neurológico.

Quatro meses após a alta foi consultado ambulatorialmente $e$ encontrava-se bem $e$ as. sintomático.

\section{DISCUSSAO}

O Quadro I mostra de maneira sumariada as caracteristicas de 4 casos de paracoccidioido. micose ocular com envolvimento do trato uveal existentes na literatura e do presente relato. $O$ paciente de DANTAS \& col.5 também sofreu enucleaçäo mas o estudo anátomo-patológico somente demonstrou um comprometimento inflamatório de íris, poupando a corólde posterior e a câmara vitrea e sem detectar-se a presença do fungo. Este havia sido previamente isolado por meio de cultura do humor aquoso.

Nos casos de CONTI-DIAZ \& $\mathrm{col}^{4}{ }^{4}$, BRICK ${ }^{3}$ e de BONOMO \& col, ${ }^{2}$ a lesão localizava-se na coróide e os diagnósticos foram firmados por exclusăo de outras possivels etiologias, em presença da doença micotica disseminada nestes

Q U A D R O I

Casos de paracoceidioidomicose disseminada eom envolvimento do trato uveal

\begin{tabular}{|c|c|c|c|c|c|c|}
\hline Cavo & Sexo & Idade & Diagndstico & Tratatnento e evoluçâo & Local & Outros locals \\
\hline $\begin{array}{l}\text { CONTI-DLAZ \& } \\
\text { eot. (1964) }\end{array}$ & $\mathbf{M}$ & 38 & Pundosicopis & $\begin{array}{l}\text { Anfotericina } B \\
\text { Regrenstio da lesão } \\
\text { após } 1 \text { mês }\end{array}$ & Coroide & $\begin{array}{l}\text { Orofaringe } \\
\text { Pulmōes } \\
\text { Pele }\end{array}$ \\
\hline ERICK (1960) & $\mathbf{M}$ & 28 & Fundoscopis & $?$ & Coróide & L.infonodos \\
\hline $\begin{array}{l}\text { DANTAS \& col.t } \\
\text { (1971) }\end{array}$ & M & 55 & $\begin{array}{l}\text { Cultura de } \\
\text { humor squoso }\end{array}$ & Entuclesçăo & fris & $\begin{array}{l}\text { Lifinfonodos } \\
\text { Mucosi bucal } \\
\text { Pulmoes } \\
\text { Pole }\end{array}$ \\
\hline $\begin{array}{l}\text { BONOMO \& col.' } \\
\text { (1982) }\end{array}$ & $\mathbf{F}$ & 48 & $\begin{array}{l}\text { Angiofluores- } \\
\text { ceinografia }+ \\
\text { fundoseopia }\end{array}$ & $\begin{array}{l}\text { Anfoterieina B } \\
\text { Lesilo estável após } \\
1 \text { atio }\end{array}$ & Cordide & $\begin{array}{l}\text { Linfonodos } \\
\text { Rinofaringe } \\
\text { Pulmöes }\end{array}$ \\
\hline $\begin{array}{l}\text { PRESBNNTE CASO } \\
\text { (1985) }\end{array}$ & $\mathbf{M}$ & 50 & $\begin{array}{l}\text { Anditomo-pato: } \\
\text { Iogtco }\end{array}$ & Fruclesçấ & Conoide & $\begin{array}{l}\text { Puimoles } \\
\text { Mucoss buca: } \\
\text { Supra-renal }\end{array}$ \\
\hline
\end{tabular}

realizada uma tomografis computadorizada e esta mostrou uma pequena área de baixa atenuacilo em regiảo parietal direita, sem acuimu. lo de contraste, compatível com infarto cere. bral, sem outras lesర̄es. pacientes. No nosso caso hal a presença do fungo em meio a intensa lesão inflamatória gra. nulomatosa, e apesar da proximidade anatômica importante, nāo há qualquer indício atual de comprometimento do sistema nervoso centrals. 
ARRUDA, W. O.; CANTO, M. A. S.; LODDO; G.; REBUFFI, V. F. \& CARDOSO, M. de A. - Paracoccidioidomicose ocular. Relato de um caso com coriorretinite posterior. Rev. Inst. Med. trop. Sáo Paulo, 28:190-193, 1986.

seja pelo estudo do líquido cefalorraquidiano ${ }^{10}$, seja pela tomografia computadorizada 9 .

A raridade tanto do acometimento ocular como do acometimento do sistema nervoso central pela blastomicose, mesmo nas formas mais disseminadas, não permite concluir-se sobre a relaçăo entre comprometimento do SNC e do aparato visual.

\section{SUMMARY}

\section{Ocular paracoccidioidomycosis case report}

A case of paracoccidioidomycosis with ocular involvement is described. For the first time the finding of the fungii in the chroidal granulomatous lesion is reported.

The Authors review the cases of ocular paracoccidioidomycosis with uveal involvement already described in the available literature and analyse their clinical and pathogical characteristics, including this present one.

\section{AGRADECIMENTOS}

A Sra. Alice Gaspari Castelan pelo auxilio no preparo deste manuscrito. As técnicas sorológicas para paracoccidioidomicose foram montadas e padronizadas pelo Prof. Flávio Telles de Queiroz Filho, Laboratório de Micologia da Universidade Federal do Paraná.

\section{REFERENCIAS BIBLIOGRAFICAS}

1. BARBOSA, W. \& DAHER, R. R. - Blastomicose sulamericana. In: VERONESI, R., ed. - Doenças infecciosas e parasitárias. 7.a ed. Rio de Janeiro, Guanabara Koogan, 1982. p. 638-651.
2. BONOMO, P. P.; BELFORT JR., R.; TSUNECHIRO, J. Y. \& FILHO, O. G. - Choroidal granuloma caused by "Paracoccidioides brasiliensis". Mycopathologia (Den Haag), 77: 37-41, 1982.

3. BRICK, M. - Ocular involvement in lymphatic paracoccidioidomycosis. Acta ophthal. (Kbh.), 47: 991-997, 1969.

4. CONTI-DIAZ, I. A.; CABOT, P. E. ; ARRYGONI, N. \& GEZUELE, E. - Blastomicosis sulamericana disseminada com coriorretimitis nodular posterior. An. Fac. Med, Montevideo, 49: 541-548, 1964.

5. DANTAS, A. M.; CURI, R.; COSTA, J. D.; AZULAY, R. D.; QUEVEDO, L. P.; MANHAES, L. F.; DE PAULA, M. E. \& DE MELLO, L. R. P. - Sobre um caso de blastomicose sul-americana com lesāo ocular. Rev, bras. Oftal., 30: 313-321, 1971.

6. DEL NEGRO, G. - Outras lesões. Formas de ocorrência rara e associaçāo com outros processos. - In: DEL NEGRO, G.; LACAZ, C. da $\mathrm{S}$. \& FIORILLO, A. M. - Paracoccidioidomicose. Blastomicose sul-americana. Sāo Paulo, Sarvier; Editora da Universidade de São Paulo, 1982. p. 229-243.

7. LACAZ, C. da S.; PORTO, E. \& MARTINS, J. E. C. - Micologia média. 7." ed. São Paulo, Sarvier, 1984. p. 189-223.

8. LUTZ, A. - Uma mycose pseudococcidica localisada na boca e observada no Brazil. Contribuição ao conhecimento das hyphoblastomycoses americanas. Bras.-méd., 22: $121.124,141-144,1908$

9. MINGUETTr, G. - Tomografia Computadorizada dos granulomas blastomicóticos encefálicos. Rev. Inst. Med. trop. S. Paulo, 25: 99-107, 1983.

10. NOBREGA, J. P. S.; MATTOSINHO-FRANCA, L. C. \& NETTO, A. S. F. - Neuroparacoccidioidomicose. In: DEL NEGRO, G.; LACAZ, C. da S. \& FIORILIO, A. M. - Paracoccidioidomicose. Blastomicose sul amoricana. São Paulo, Sarvier; Editora da Universidade de Săo Paulo, 1982. p. 221-227.

Recebida para publicaçăo em $30 / 7 / 1985$. 